\title{
Health, social and emotional problems of college students.
}

\author{
Dr. Priyanka Sharma, Nisha Saini. \\ Assistant Professor Deptt. Of Life Long learning, University of Jammu \\ M.A Student.
}

\begin{abstract}
Adjustment is one of the most important psychological activities of human being. Life is a process of adjustment. If anyone wants satisfaction in life, then one has to adjust with their environment.

The present study was conducted on the students of two colleges-one urban and one rural of Jammu region. The main objective of the study was to identify the adjustment problems among college going students. The three dimensions of adjustment i.e. Health, Social and Emotional were studied across two sexes i.e. Boys and Girls and in rural and urban areas. A sample of 100 students (50 Boys and 50 Girls) was selected by using stratified random sampling technique from two colleges. Adjustment Inventory for college students by A.K.P Sinha and R.P Singh (1995) was administered. To find out the significant difference of adjustment across different variables $t$-test was applied.

The findings of the study revealed that Girls are average in the dimensions of health and social adjustment and unsatisfied in emotional areas. Boys are average in the dimensions of social adjustment and unsatisfied in health and emotional areas. There is no significant they differ significantly difference between health, social and emotional adjustment of Girls and Boys. There is a significant difference between health and emotional adjustment of urban and rural college students but they do not differ significantly in social adjustment
\end{abstract}

Keywords: Adjustment problems, health, social and emotional adjustment, gender difference, locality.

\section{Introduction}

"Happiness Comes From..........Some Curious Adjustment to Life."

In this rapid changing world adjustment is a persistent feature of human personality. Unless a person is not able to adjust himself to the environment he/she cannot develop his/her wholesome personality. A man of adjusting nature can lead a cheerful and wholesome life but a less adjusting nature always leads a depressed and unhealthy life. Adjustment is a process by which an individual learns certain ways of behaviour to cope with the situation which he/she attains through harmony with his/her environment. After completing secondary school many students join colleges and other institutions. The transition to college can be a stressful experience for students. College is an exciting time of life one filled with many profound transitions in preparation of an exciting and fulfilling future. They have to adjust with their own changes in personality on one side and the changing socio-economic environment on the other side.

In recent years there has been growing interest in adolescent's transition to college and the development of socio-emotional challenges that accompany the transition, only half of the entering college students manage to finish their degree in a specified period and the remaining half dropout at some stage. United States Department of Education, (2001) in a study concluded that college students are at risk for failure to graduate. Belch, Gebel and Mass (2001) also noticed that academic performance made a difference in the retention of students also they found that more adjusted students in the institution have average \& more success in college and life in general.

In a study conducted by Gerdes \& Mallinckrodt, (1994) found that the shift between high school and colleges can be challenging and many changes occur in emotional, social and academic adjustment. Adjustment difficulties, loneliness and depression are much more common now a day among college students than their peers who are not in college. In the modern society, life is becoming very complex \& conflicting day by day. If a person is well adjusted only then one can survive without psychological stress which may result in maladjustment. Hence adjustment is very important in one's life.

Anonymous (2004) has examined trends between 1983 and 2003 in young people's emotional health \& well being, as reported through their young people and health survey has found that young people are increasingly more likely to worry quite a lot about college and career problems. The Psychologists are more concerned with adjustment to demands of two kinds. One is primary, a social demand and other is an internal biologically based demands often or in conflict with internal social demand. 


\section{Concept Of Adjustment}

The term adjustment refers to the extent to which an individual's personality functions effectively in the world of people. The concept of adjustment was originally a biological one and was used in Darwin's (1859) "Theory of Evolution". It was termed as adaption. Darwin maintained that only those species that who are fit to adapt to the hazards survived (Survival of the Fittest). The biological concept of adaptation has been borrowed by the physiologist and renamed as "adjustment". Adjustment and adaptation together represent the functional perspective for view and understanding human behaviour i.e. behaviour is seen as having the function of mastering demands that are made upon the individuals by his environment human behaviour can be understood by conceiving it as an adjustment to psychological demands.

Some of the definitions of adjustment are as:-

Adjustment: Adjustment may be defined as a process of altering behaviour to reach a harmonious relationship with the environment.

Lazarus (2001) defined that the adjustment as a ways of managing and consists of coping with various demands and process of life.

Good (1959) state that adjustment is the process of finding and adopting modes of behaviour suitable to the environment or the changes is the environment.

Paranmeswaran \& Beena (2004) defined adjustment is a process which a living organism acquires in a particular way of acting or behaving or changes an existing form of behaviour or action.

\section{Health Adjustment:}

\section{Areas Of Adjustment:}

Heightened emotionality even when the expressions are controlled tends to make one nervous or ill. It is often accompanied by specific mannerism such as nail biting or giggling, creates the impression that the person is silly or immature. Heightened emotionality is especially common among pre pubescent girls at the time of menstrual period of students. Baker and Siryk (1984) assessed the psychological adjustment of students in college. They recognized the importance of psychological adjustment, as well as the importance of academic and social integration into college systems.

\section{Social Adjustment:}

Social adjustment is the most difficult developmental task of student's life. This adjustment has to be done with members of the opposite sex in a relationship that never existed before and to adults outside the family and school environments. Early adults are a period of social expansion and development. Guo (1998) found that females scored higher than males on reading recognition and comprehension tests after controlling family background factors.

\section{Emotional Adjustment}

Frequent, intense and apparently unjustified emotional outbursts lead others to judge the individual as "Immature". Suppression of emotional expression results in moodiness which tends to make the individual rude, un co-operative and pre-occupied with self.

A satisfactory state of personal and emotional adjustment may be said to exist when an individual's physical and Psychological needs can be satisfied by socially acceptable patterns of behaviour. Child's emotions exercise a potent influence upon his attitudes and behaviour. Unbridled emotional reactions may therefore, interfere seriously with young person's power to use the freedom of decision making and behaviour. Those students whose pattern satisfied with their life styles, whose urges and desires are met with satisfactions tends to enjoy life to the fullest and become emotionally adjusted. Some students adjust well to the college environment whereas others struggle with the transition some leaving school entirely (Ezezek, 1994; Holembek \& Wandrei, 1993).

\subsection{OPERATIONAL DEFINITIONS}

The definitions of the terms used in the present study are as:

Adjustment: Adjustment may be defined as a process altering behaviour to reach a harmonious relationship with the environment. When people say they are in an "Adjustment Period" they typically mean they are going through of change and are searching some level of balance or acceptance with the environment, others or themselves.

Health Adjustment: It is the ability to adjust physically and mentally in different type of atmosphere without causing any impact on health. 
Social Adjustment: This means a harmonious relationship with the students and teachers, proper understanding of social needs, requirement's and group goals and meeting respectively to the social requirements of the home, peer groups, culture and the community.

Emotional Adjustment: Emotional adjustment referred to as personnel adjustment or psychological adjustment is the maintenance of emotional equilibrium in the face of internal and external stressors.

Locality: Area or place where the college is situated i.e. rural or urban.

Gender: It is evident that the gender refers to male (Boy student) and Female (Girl student).

\subsection{STATEMENT OF THE PROBLEM}

"To study the adjustment problems of students in selected urban and rural colleges of Jammu region"

\section{Review Of Literature}

In the words of (Brog) "Literature in any field forms the foundation upon which all the future works are build''. Study of related literature implies locating and evaluating research reports as well as reports of the casual operation and opinion that are related to the individuals planned research project. It also takes into account the advantage of the knowledge, which has already been accumulated in the past as a result of constant human endeavor. A review of related literature gives the scholar an understanding of previous work that has been done in his/her fields/area of research and what still remains to be done.

The related studies in any field forms the foundation upon which future work will depend. Review of related literature makes the investigator fully aware with the previous work that has been done. It also provides an opportunity of gaining insight into the method, measures, subject and approaches employed by the other researchers. A careful review of research, journals, books, dissertations, thesis and other sources of information about the problem to be investigated is one of the important steps in the planning of any research studied. In the present study the investigator has reviewed the researches done in the field of adjustment problems among college students.

Roy, Ekka and Ara(2011) observed that Girl students were better adjusted in all areas of adjustment than Boy students.

Lama (2010) reported that there is a great tendency for female students to experience adjustment problems more than males. This finding implies that male students are better adjusted in overall adjustment on the campus as compared to female students.

Rahamtullah (2007) stated that boys are significantly better adjusted than girls on the emotional adjustment area.

Kurvilla (2006) reported that urban were well adjusted than rural students in all areas of adjustment problems.

Enochs and Roland (2006) studied (511) male and female university students in the first year, where he studied the nature of the environment, gender and the relation with level adjustment of social in the university, the result indicate out that males are more adjusted than females.

Shalu and Audichya (2006) assessed and compared the school adjustment of 60 rural adolescents with reference to their emotional and social sphere. The sample consisted of 30 rural boys and 30 rural girls between the age group of 15-18 years studying in government co-educational school only. The adjustment inventory for school students constructed by Sinha and Singh (1984) which was modified by the investigator was used for data collection. They reported a significant difference was observed in social and emotional adjustment.

Denir Urberg (2004) study, examined the relation of friendship with the emotional adjustment for students, a sample of 618 adolescents results showed that a strong social relationship with a positive impact on the adjustment, but females are more impact than males in terms of the kind of social relationship.

Nanda (2001) conducted a study on 280 urban and rural college students on health adjustment and reported that urban students had better health than the rural students.

Dutta etal (1998) conducted a study on social adjustment of students on 200 adolescents draw equally from Assam Agricultural University and Kendriya Vidalaya district of Jorhat, Assam. Sample of 50 boys \& 50 girls of age group 19-21 years was selected. Adjustment inventory for college students developed by Sinha and Singh (1980) was administered results revealed that no significant difference among the boys and girls in the area of social adjustment. 
Jain and Jandu (1998) conducted a study on adjustment areas on a sample of 240 students (14-19 years). Adjustment inventory for school students developed by Sinha and Singh (1984) was used to measure the adjustment of the students. They found that girls were better adjusted than boys.

Muni and Pavigrahi (1997) conducted a study on emotional, social and total areas of adjustment. The sample was consisted of 80 students, ( 40 boys and 40 girls) of two different schools of Berhampur Orissa. They found that girls were better adjusted in the all the areas of adjustment pattern than boys.

Dutta et.al.(1997) focused on health adjustment of 200 students drawn randomly from Assam Agricultural University and Kendriya Vidalaya district of Jorhat, Assam. The total Adjustment inventory for college students developed by Sinha and Singh (1980) was administered.

The results reported that boys to be better adjusted than girls in the areas of health adjustment.

Mc Whitner (1997) in his study of 625 college students, found that female students are more likely to experience loneliness and social isolation than their male pears. This study found that female students had a more difficult time fitting into the college environment and were less likely to be involved in college activities and less likely to have leadership positions in campus organizations.

Cook (1995) calculated that female students are found to demonstrate more adjustment problems such as establishing social relationship in college compared to the male students.

Singh (1995) observed that adolescent girls are better adjusted in the areas of emotional where as adolescent boys were better adjusted in the area of health and social adjustment.

Anita (1994) provided an insight into the gender differences in adolescents self concept and adjustment. It was depicted from the results that girls better adjusted in emotional, social, educational and total areas of adjustment areas of adjustment compared to boys.

Sujatha et.al (1993) studied social adjustment problems among urban \& rural college students and reported a significant difference in the social adjustment of urban and rural college students.

Thirugnana Sambadam (1990) also supported that boys were better adjusted than girls on a sample of 388 students of $9^{\text {th }}$ grade.

Leelavathi (1987) in her study in Dgarwad City on 450 samples found that males had good social and total adjustment than females.

Mohsin, et.al, (1985) have reported in a study conducted that male subjects have higher adjustment then female subject.

Dhoudiyal (1984) studied on 276 emotionally disturbed adolescents, who were identified from randomly selected rural and urban intermediate colleges with the help of emotional disturbance inventory developed by Rawal (1983). The result reveal that rural college students were more emotionally disturbed than the urban college students.

Sulthana et.al (1981) conducted a comparative study on personality adjustment among rural and urban students. The sample of study consists of 200 urban and rural students study compared the adjustment of rural and urban group on social, emotional, health, home and family aspects. Results revealed that students of urban area were more adjusted as compared to rural college students.

Pathak (1970) studied on adjustment of 400 students (200 boys \& 200 girls) with age range of 14-16 years. The sample was selected randomly from six high schools of Jabalpur in Madhya Pradesh. Saxen's Vyakiya ParaksPrashnavali (MA-62) was used to measure the adjustment and reported that girls were facing more problems than boys in the areas such as social and emotional adjustment. They were found to be comparable in the areas of social and emotional adjustment as there was no significant difference.

Palsane (1970) explored the role of health adjustment and parental education on personal adjustment on a sample of 85 students out of which 47 were boys and 38 were girls. The results revealed that students with good health were high in over all adjustment. He also reported that students with good parental education were better adjusted.

Langner (1962) conducted a study on health adjustment among rural and urban college students and conclude that rural students face more problems than urban students, especially girls.

\section{Research Methodology}

Research methodology is a scientific procedure of looking at research issues. It is a science of studying how research is to be carried out. Essentially, the procedure by which researchers go about their work of describing, explaining and predicting phenomena is called research methodology. It is also defined as the study of methods by which knowledge is gathered. Its aim is to give the work plan of research. It is necessary for a researcher to design a methodology for the problem chosen. One should note that even if the method considered in two problems is same the methodology may be different. It is important for the researcher to know not only the research methods necessary for the research under taken but also the methodology. 
The present chapter throws light on the research methodology adopted for the present study. Here research objectives and design of the study i.e. sample for the study and selection of the research instrument are discussed. Methods for the collection of the data and statistics for analyzing the data have also been discussed.

\section{Rationale}

The process of adjustment starts right from the birth of the child and continuous till his death. Each person constantly strives to meet his needs and reach his goals. At the same time he is under pressure of the environment to behave in certain ways.

After completing high school many students join some colleges and professional institutions. Attending college is one of the first major life transitions for many young adults. Some students are excited to take on the new experiences of campus life, while others feel apprehensive about making this change.

College adjustment means the capacity of a person to respond to the college environment which includes curricular and co-curricular activities college brings a unique opportunity. While each person's problems are unique to their current circumstances, we know that there are a few problems that almost all college students deal with at least once during their time at school.

The college students' encounters are due to the transition between their life experiences at the college level. There is a challenge of separation between their home environment and college environment. Students face the challenge of adjusting with the roommates who way have very different boundaries and individual needs than family and friends from home. They also face the problems related to health, social emotional. Because of these problems only half of entering college students manage to finish their degree within a period and the remaining half drop out together (Wintre and Bowers, 2007). It is all due to

$>$ Environmental Changes.

$>$ Social Pressure.

$>$ Role Changes.

$>$ College Achievements.

$>$ Parental Favoritism etc.

Thus the need of the hour is to concentrate on the reasons which are responsible for the weak adjustment of the students with in college environment in particular and life in general. Thus it would be useful to look and understand the adjustment problem of college students.

\section{OBJECTIVES}

1. To study the health, social and emotional problems being faced by the girls students studying in the colleges of Jammu.

2. To study the health, social and emotional problems faced by the boys students studying in the colleges of Jammu.

3. To study the difference between the health, social and emotional problems faced by the girls and boys students studying in the colleges of Jammu.

4. To study the difference between the health, social and emotional problems faced by the students studying in the urban and rural colleges of Jammu.

\section{HYPOTHESIS}

1. The girls adjustment level related to health, social and emotional environment shall be good or excellent.

2. The boys adjustment level related to health, social and emotional environment shall be average or unsatisfactory.

3. There will be a significant difference between the health, social and emotional problems faced by the girls and boys students.

4. There will be a significant difference in health, social and emotional problems faced by the students studying in the urban and rural colleges.

\section{VARIABLES}

Variables are qualities, properties or characteristics of person, things or situations that change or vary.

\section{Independent Variables}

An independent variable is the variable that stands alive and does not depend on any other.

In this study independent variables are

Gender: Boys and girls

Locality: Urban and Rural 


\section{Dependent Variables}

The dependent variable is the variable that the researcher is interested in understanding, explaining or predicting.

In this study dependent variables are adjustment problems of college student's i.e. Health, Social and Emotional problems.

\section{SAMPLE}

One hundred students (50 boys and 50 girls) in the age group 18-21 years were selected by using stratified random sampling method from two different colleges (one rural and one urban) of Jammu region.

\section{SAMPLING TECHNIQUES}

In the present study the investigator used the stratified random sampling technique. The stratified sampling is a method of sampling that involves the division of a population into smaller groups known as strata. A random sample from each stratum is taken in a number proportional to the stratum's size when compared to the population. These subsets of the strata are then pooled to form a random sample.

\section{SAMPLING DESIGN}

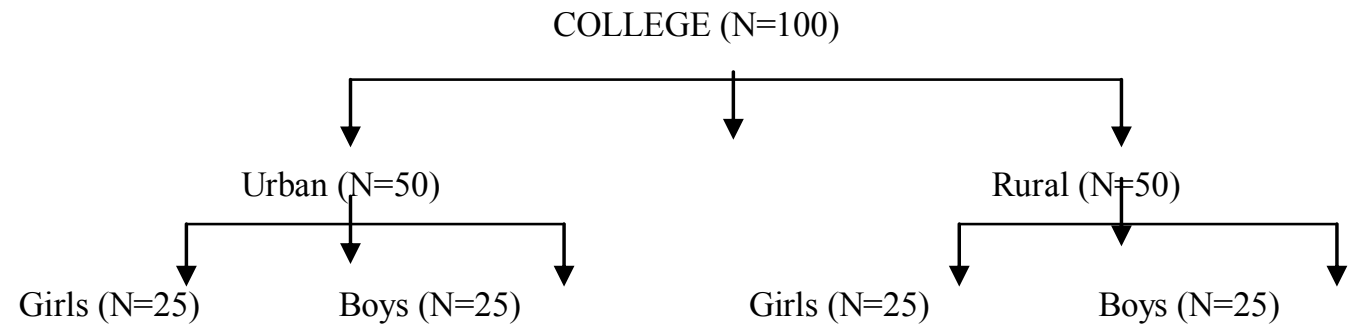

\section{DATA COLLECTION PROCEDURE}

The data collected by using stratified random sampling technique from two colleges

1) GGM Science college Jammu and

2) Govt. Degree College Bishnah

The administrations of the respective institutes were informed and verbal consent to conduct the study was taken. Consent was also taken from the respondents after explaining to them the purpose of the research as well as the academic use of the data later on. After rapport formation the questionnaires were given individually to the subjects. Before administering the test the respondents were briefed about the test in detail. They were assured that their responses would be kept confidential and that the research is for educational purpose. Instructions were read clearly by the investigator and simple classifications of word meanings were given on request without influencing responses.

\section{TOOLS TO BE EMPLOYED AND ITS DESCRIPTION}

The tool used to measure the adjustment level of students is:

Adjustment Inventory for College Students

- $\quad$ Developed by A.K.P Sinha and R.P Singh in 1995.

- The inventory has been designed in English/Hindi for College Students of India.

- The Inventory has 65 items which measure adjustment of the college student in the following areas i.e.,

a) Health (15 items)

b) Social (19 items)

c) Emotional (31 items)

Each item has two options for answering i.e. Yes or No.

Split half reliability and test retest reliability for the test was 0.94 and 0.93 respectively, which indicates that the scale has excellent psychometric properties.

The responses were scored as per the manual

a) Health Adjustment: - High scales in health area reflect unsatisfactory adjustment.

b) Social Adjustment: - Students scoring low in social adjustment are submissive and retiring while high scores indicate aggressive behaviour.

c) Emotional Adjustment: - High score indicate unstable emotion \& low score indicate emotionally stable. 
STATISTICS TO BE USED

Mean: - The mean is obtained by dividing the sum of observed values by the number of observations, $\mathrm{n}$.

i.e.

$\begin{array}{lll}\bar{x}= & \sum \frac{x}{n} & \\ \text { Where, } \bar{x} & = & \\ \sum x & = & \text { Symbol for Mean } \\ n & = & \text { number of observations. }\end{array}$

Standard Deviation:-The Standard deviation is the actual distance between the actual data and the mean. The statistics from of standard Deviation is

S.D. $\quad=\quad \sqrt{N \sum \mathrm{x} 2-\left(\sum \mathrm{x}\right) 2}$ $\mathrm{N}$

T-test: - used to study the significant difference in the adjustment problems of college students. Formula for Ttest is, $\mathrm{T}=\bar{x}_{1}-\bar{x}_{2}$

$\begin{array}{lll}\text { Where, } & & \\ x_{1} & = & \text { Mean for group 1. } \\ x_{2} & = & \text { Mean for group 2. } \\ \mathrm{n}_{1} & = & \text { number of People in Group 1 } \\ \mathrm{n}_{2} & = & \text { number of People in Group 2 } \\ \mathrm{S}_{1}{ }^{2} & = & \text { Variance for Group 1 } \\ \mathrm{S}_{2}{ }^{2} & = & \text { Variance for Group 2 } \\ \mathrm{S}_{1}{ }^{2} & = & \frac{\sum(\mathrm{X}-\bar{x})^{2}}{\mathrm{n}-1}\end{array}$

\section{TABULATION AND ANALYSIS}

Analysis of data means studying the tabulated material in order to assess the inherent facts or meanings. It is the process by which sense and meaning are made of the data gathered in qualitative research, and by which the emergent knowledge is applied to sample's problem. The purpose of analysis is to reduce data into intelligible and interpretable form so that the relation of research problem can be studied and tested. Analysis of the study should relate to the objectives and research hypothesis. Collection of data has no meaning unless it is tabulated properly, analysed and interpreted by sophisticated statistical technique. A systematic and sufficient treatment of the tabulated data is essential for drawing valid conclusion. It includes the breaking down of the complex factors into simpler parts and putting the parts together in new arrangements for the purpose of interpretation. It requires an alert, flexible and open mind

The data collected in the present study is represented in the tabulated form in the table given below.

Table 4.1: Mean and S.D scores of Girls student for three adjustment dimensions,.

\begin{tabular}{|l|l|l|}
\hline Adjustment Areas & Mean & S.D \\
\hline Health & 6.88 & 2.68 \\
\hline Social & 9.1 & 2.73 \\
\hline Emotional & 18.38 & 4.04 \\
\hline
\end{tabular}

Table indicating the mean scores and standard deviation of Girls student for three adjustment dimensions followed by Health, Social and Emotional adjustment. 
Health, social and emotional problems of college students.

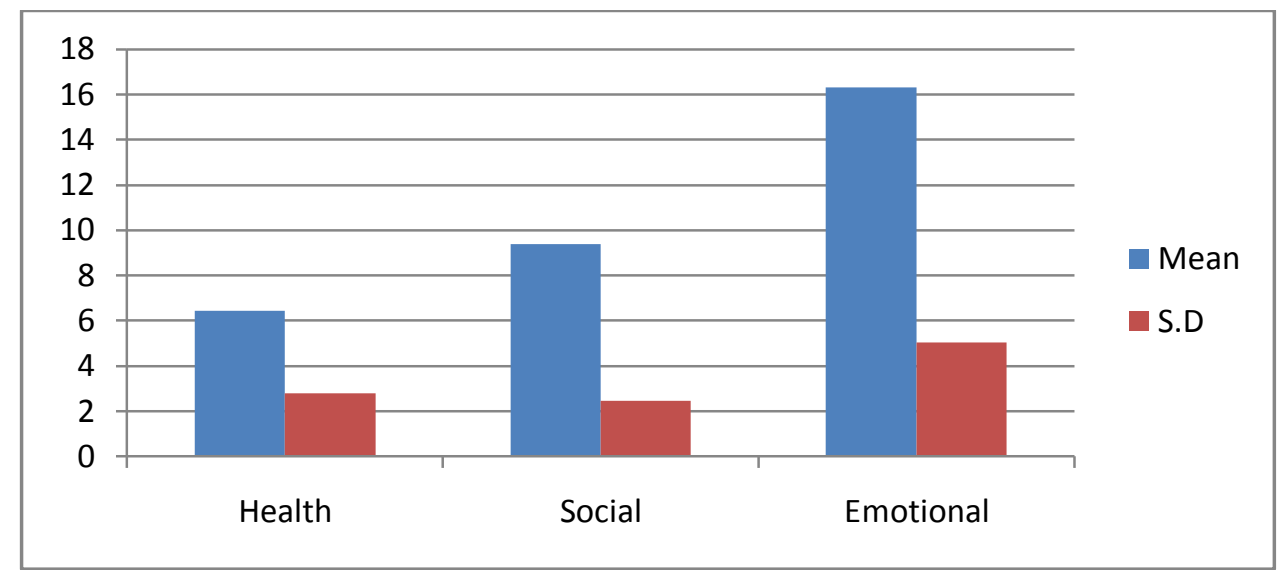

Figure 4.1(A): Graph showing Mean and S.D scores of Girls student for three adjustment dimensions.

Table 4.2: Mean and S.D scores of Boy students for three adjustment dimensions.

\begin{tabular}{|l|l|l|}
\hline Adjustment Areas & Mean & S.D \\
\hline Health & 6.44 & 2.81 \\
\hline Social & 9.38 & 2.45 \\
\hline Emotional & 16.3 & 5.03 \\
\hline
\end{tabular}

Table indicating the mean scores and standard deviation of Boys student for five adjustment dimensions followed by Health, Social and Emotional adjustment.

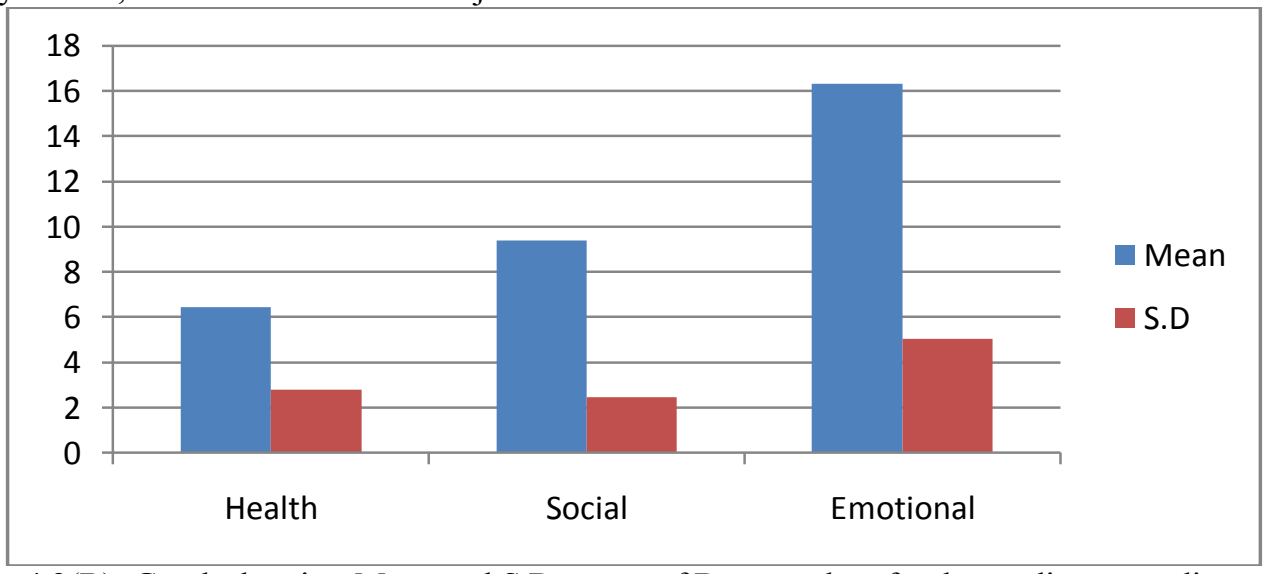

Figure 4.2(B): Graph showing Mean and S.D scores of Boys student for three adjustment dimensions.

Table 4.3: t-value of health adjustment dimension for Girls and Boys.

\begin{tabular}{|l|l|l|l|l|}
\hline Group & N & Mean & S.D & t-value \\
\cline { 1 - 4 } Girls & 50 & 6.88 & 2.68 & \multirow{2}{*}{0.802} \\
\hline Boys & 50 & 6.44 & 2.81 & \\
\hline
\end{tabular}

Table indicating the mean scores and standard deviation of Girls and Boys student on health adjustment of Boys and the calculated t-value.

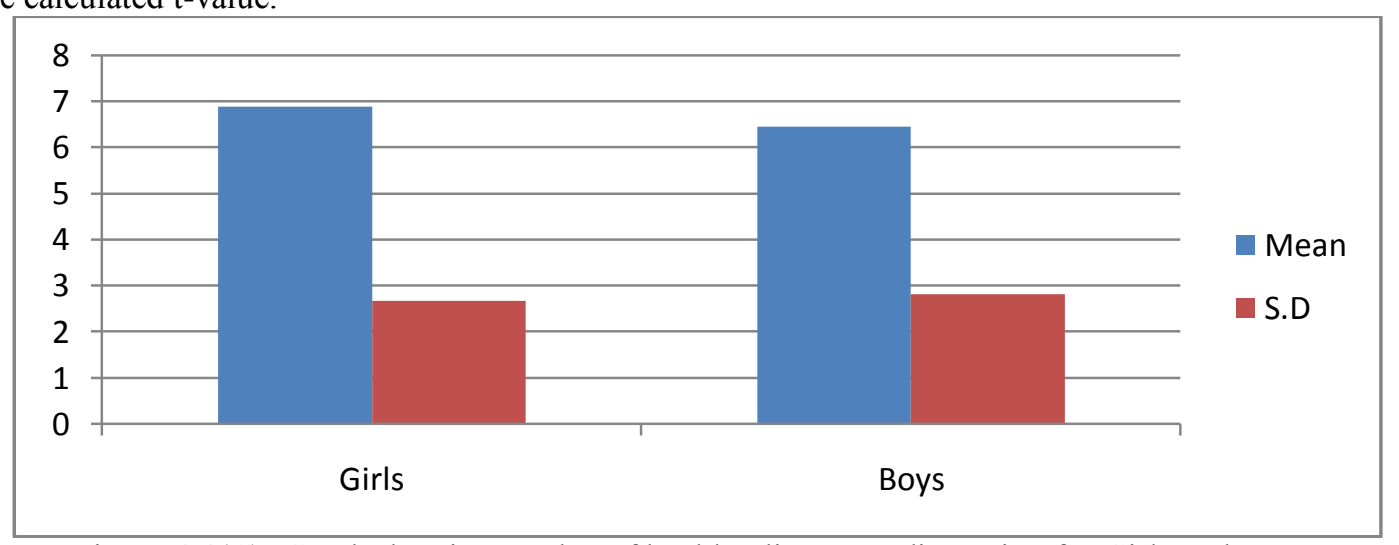

Figure 4.4(C): Graph showing t-value of health adjustment dimension for Girls and Boys. 
Health, social and emotional problems of college students.

Table 4.4: t-value of social adjustment dimension for Girls and Boys.

\begin{tabular}{|l|l|l|l|l|}
\hline Group & $\mathrm{N}$ & Mean & S.D & t-value \\
\hline Girls & 50 & 9.1 & 2.73 & 0.542 \\
\hline Boys & 50 & 9.38 & 2.45 & \\
\hline
\end{tabular}

Table indicating the mean scores and standard deviation of Girls and Boys student on social adjustment of Boys and the calculated t-value.

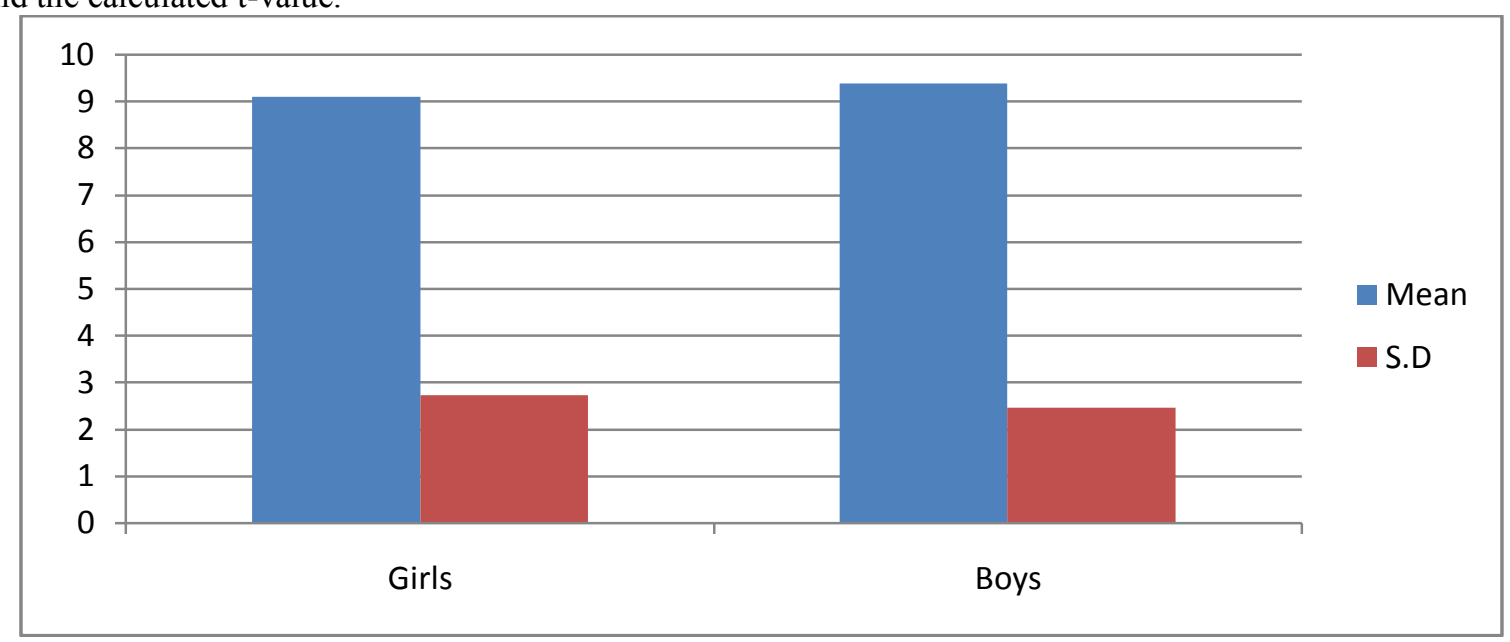

Figure 4.4(D): Graph showing t-value of social adjustment dimension for Girls and Boys.

Table 4.5: t-value of emotional adjustment dimension for Girls and Boys.

\begin{tabular}{|l|l|l|l|l|}
\hline Group & $\mathrm{N}$ & Mean & S.D & t-value \\
\hline Girls & 50 & 18.38 & 4.04 & \multirow{2}{*}{1.81} \\
\hline Boys & 50 & 16.3 & 5.03 & \\
\hline
\end{tabular}

Table indicating the mean scores and standard deviation of Girls and Boys student on emotional adjustment of Boys and the calculated t-value.

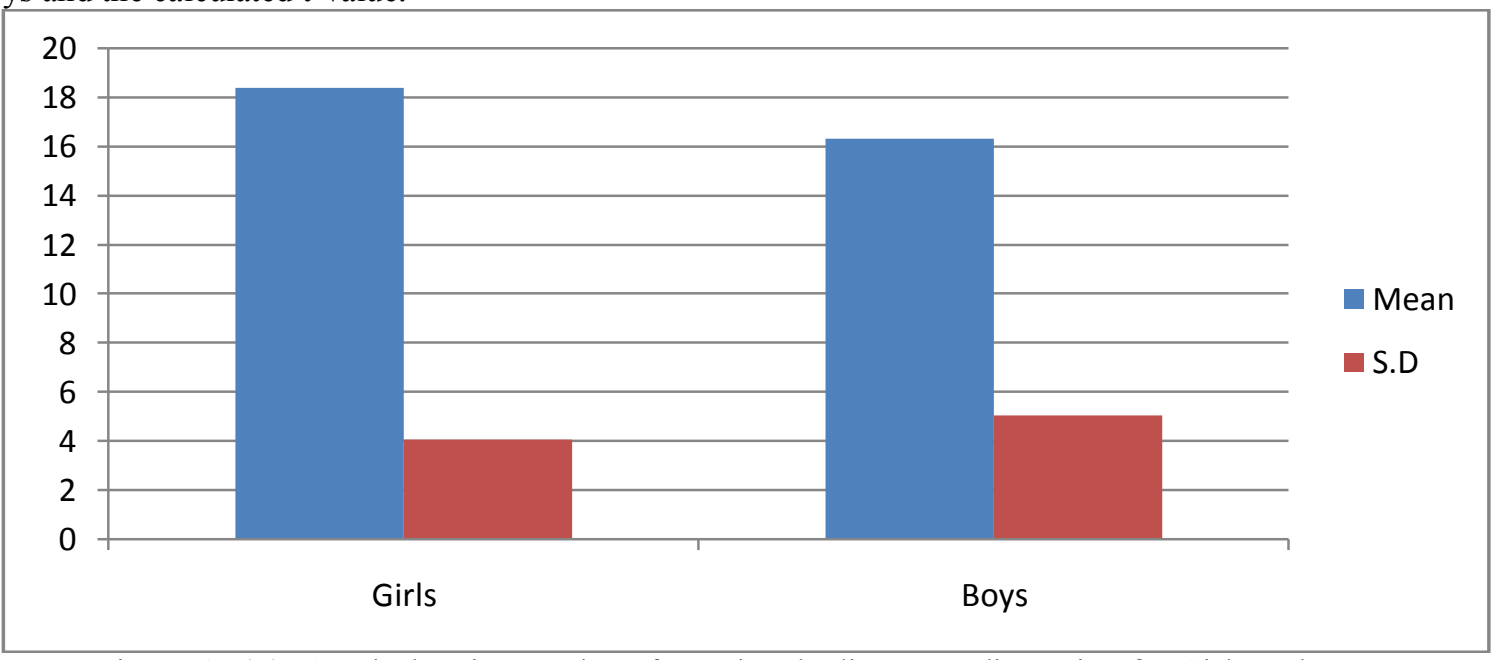

Figure 4.5(E): Graph showing t-value of emotional adjustment dimension for Girls and Boys.

Table 4.6: $\mathrm{t}$-value of health adjustment dimension for urban and rural college students.

\begin{tabular}{|l|l|l|l|l|}
\hline Group & $\mathrm{N}$ & Mean & S.D & t-value \\
\hline Urban & 50 & 5.92 & 2.43 & \multirow{3}{*}{$3.03^{*}$} \\
\hline Rural & 50 & 7.52 & 2.83 & \\
\hline
\end{tabular}

Table indicating the mean scores and standard deviation of health adjustment of urban and rural college students and the calculated $t$-value. 
Health, social and emotional problems of college students.

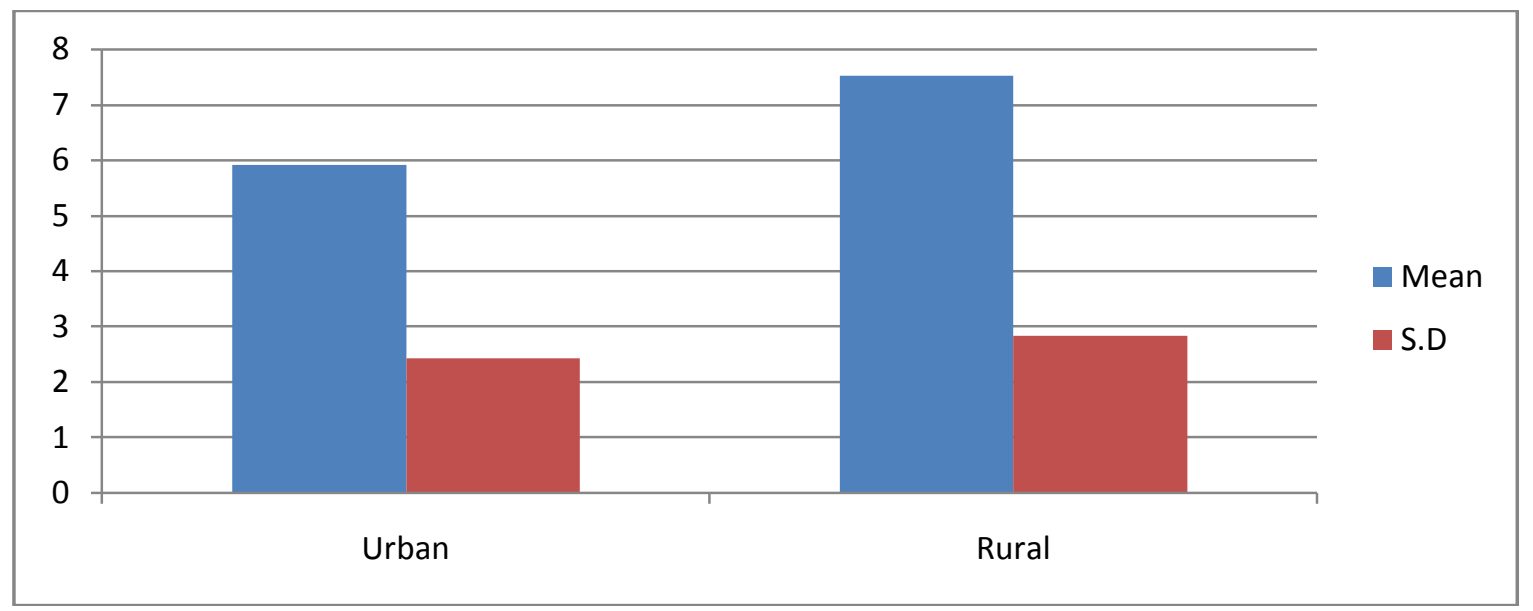

Figure 4.6(F): Graph showing t-value of health adjustment dimension for urban and rural college students.

Table 4.7: t-value of social adjustment dimension for urban and rural college students.

\begin{tabular}{|l|l|l|l|l|}
\hline Group & $\mathrm{N}$ & Mean & S.D & t-value \\
\hline Urban & 50 & 8.96 & 2.83 & 1.08 \\
\hline Rural & 50 & 9.52 & 2.31 & \\
\hline
\end{tabular}

Table indicating the mean scores and standard deviation of social adjustment of urban and rural college students and the calculated t-value.

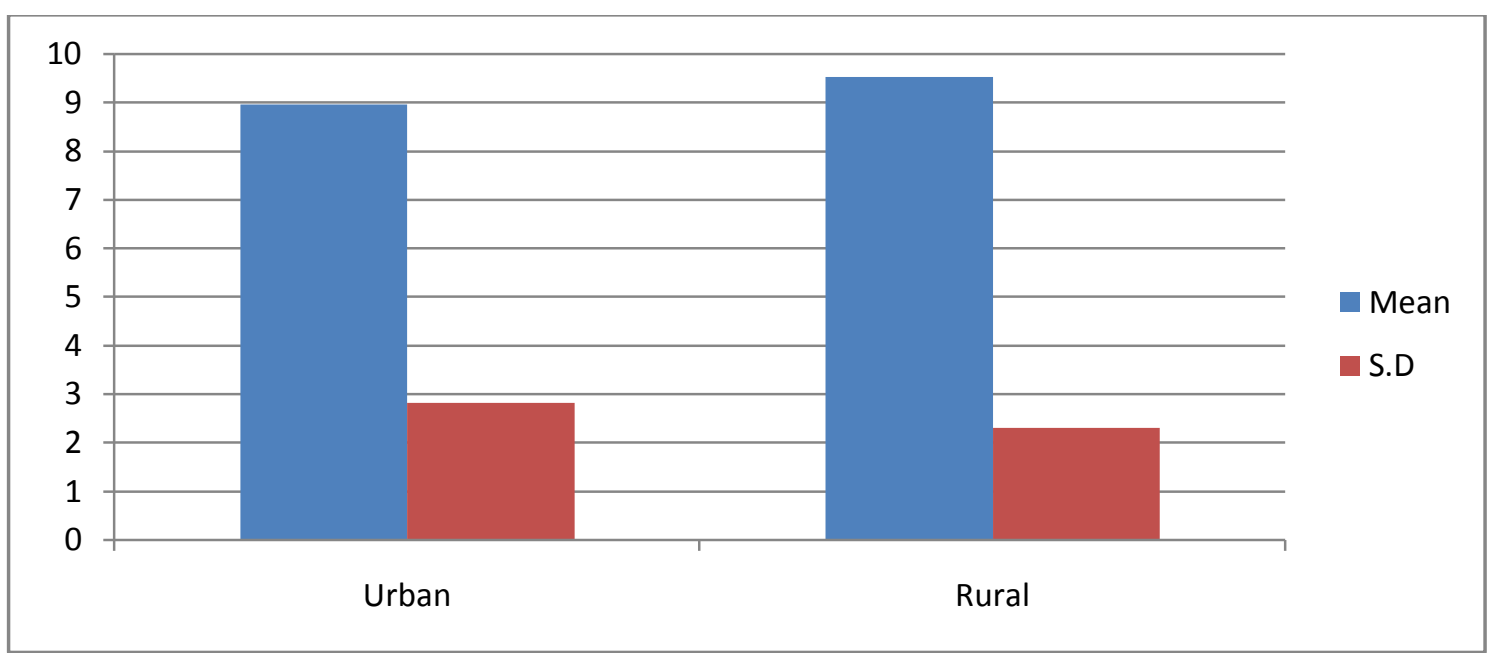

Figure 4.7(G): Graph showing t-value of social adjustment dimension for urban and rural college students.

Table 4.8: t-value of emotional adjustment dimension for urban and rural college students.

\begin{tabular}{|l|l|l|l|l|}
\hline Group & $\mathrm{N}$ & Mean & S.D & t-value \\
\hline Urban & 50 & 16.14 & 4.75 & \multirow{2}{*}{$2.66^{*}$} \\
\hline Rural & 50 & 18.54 & 4.28 & \\
\hline
\end{tabular}

Table indicating the mean scores and standard deviation of emotional adjustment of urban and rural college students and the calculated t-value. 
Health, social and emotional problems of college students.

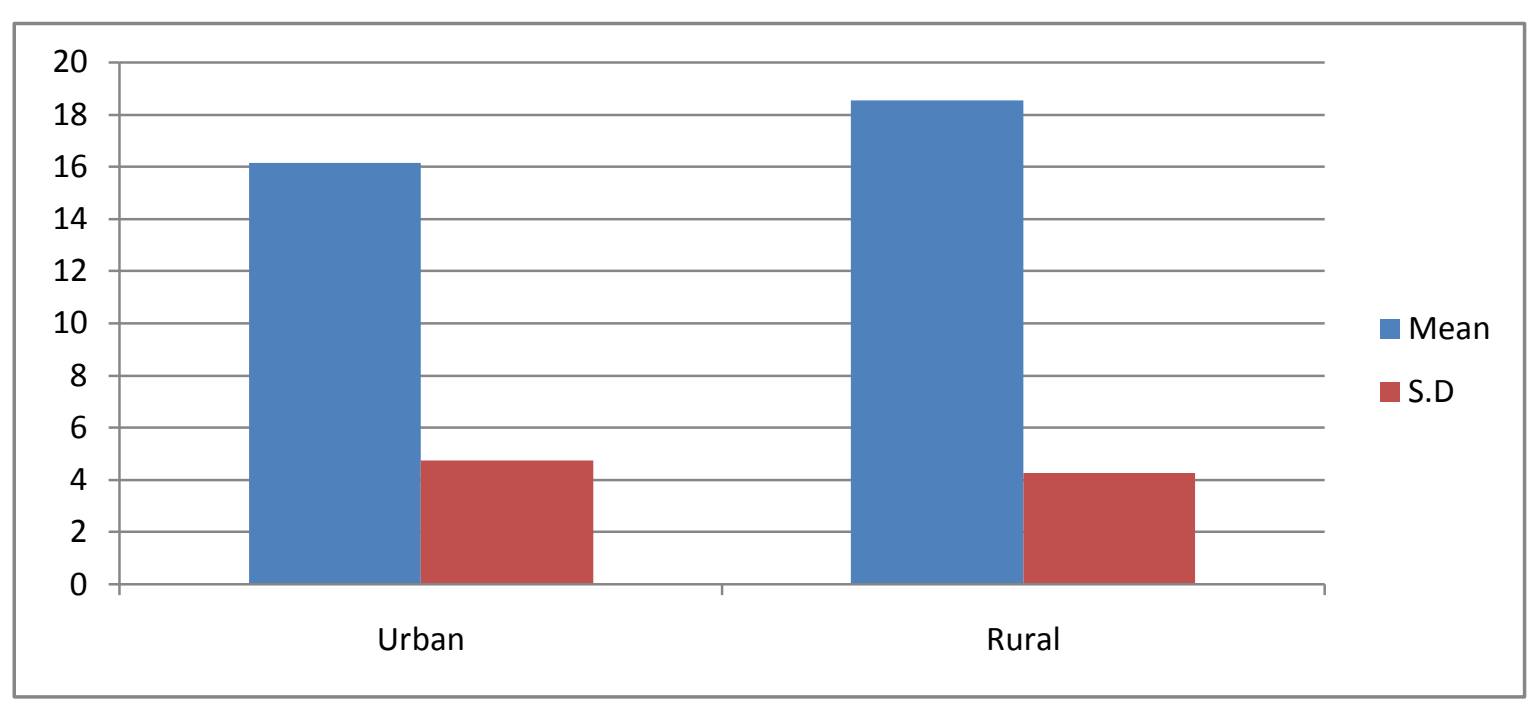

Figure 4.8(H): Graph showing t-value of emotional adjustment dimension for urban and rural college students.

\section{Interpretations And Discussions}

Table 4.1 shows the mean scores and standard deviation of Girls student for three adjustment dimensions such as Health $(\mathrm{M}=6.88$, $\mathrm{S} . \mathrm{D}=2.68)$, Social $(\mathrm{M}=9.1$, S.D $=2.73)$ and Emotional $(\mathrm{M}=18.38$, $\mathrm{S} . \mathrm{D}=4.04)$. It indicates that girls are found average in health and social-adjustment and unsatisfied in emotional adjustment when compared with Norm mean scores for girls which are as:- Health=3-6, Social=7-9 and Emotional=15-21. The given result could be due to the reason that girls are soft hearted and so they become emotional easily. There are numbers of studies conducted in this dimension which support this finding. Mc Whitner 1997 found that female student faced more problems in health and emotional dimensions of adjustment. Pathak (1970) also reported that girls were facing problems in the areas such as social and emotional adjustment. So the hypothesis 1 stating "The girl's adjustment level related to health, social and emotional environment shall be good or excellent" is rejected.

Table 4.2 shows the mean scores and standard deviation of Boys student for five adjustment dimensions followed by Health( $\mathrm{M}=6.44, \mathrm{~S} . \mathrm{D}=2.81)$, Social $(\mathrm{M}=9.38, \mathrm{~S} . \mathrm{D}=2.45)$ Emotional( $\mathrm{M}=16.3, \mathrm{~S} . \mathrm{D}=5.03)$ and .It indicates that boys are found average in social adjustment and unsatisfied in health and emotional adjustment when compared with Norms scores which are as for Health=6-8, Social=7-9 and Emotional=16-21 .The given result could be due to the reason that Boys are careless about their health and rely more on social networks and friends thus becomes easily emotional. Yet there are some studies conducted on this dimension which contradict this finding. Singh (1995) Boys are well adjusted in the area of health and social adjustment. Kasinath (1990) and Pradhan (1993) studied that boys are well adjusted in the areas of emotional adjustment. Thus the hypothesis 2 stating "The boy's adjustment level related to health, social and emotional environment shall be average or unsatisfied" is accepted.

Table 4.3 shows the $t$-value of health adjustment dimensions of girls and boys students. Since the calculated t-value 0.802 is less than critical t-value i.e. 1.98 at 0.05 level of significance. The result reveals that there is no significant difference between health adjustment of girls and boys student. Yet there are some studies which contradict this finding. Dutta et.al (1997) found that there is a significant difference between health adjustment of girls and boys student. It was found that boys were better adjusted as compared to girls in the areas of health adjustment. Singh (1995) also observed that boys are better adjusted in the area of health adjustment as compared to girls.

Table 4.4 shows the t-value of social adjustment dimension of Boys and Girls. Since the calculated tvalue $=0.542$ is less than the critical t-value i.e. 1.98 at 0.05 level of significance so the above result reveals that there is no significant difference between social adjustment of girls and boys student. Yet there are some studies which contradict this finding. Cook (1995) found that girls face more adjustment problems in social relationships as compared to boys. Another study by Muni \& Pavigrahi (1997) found that girls are better adjusted in social adjustment as compared to boys.

Table 4.5 shows the t-value of emotional adjustment dimensions of Boys and Girls student, since the calculated $t$-value $=1.81$ is less than the critical t-value i.e. 1.98 at 0.05 level of significance. So the above result reveals that there is no significant difference between emotional adjustment of girls and boys student. Yet there are some studies conducted on this dimension which contradict this finding. Muni \& Pavigrahi (1997) found 
that girls were better adjusted than the boys in emotional adjustment area. Another study Rahamtullah (2007) stated that boys are significantly better adjusted than girls on the emotional adjustment area.

Thus the Hypothesis 3 stating "There will be a significant difference in health, social and emotional problems faced by the girls and boys students" is accepted in the areas of home and educational adjustment but is rejected in the areas of health, social and emotional adjustment.

Table 4.6 shows the $t$-value of health adjustment dimensions of urban and rural college students. It indicates the mean score and standard deviation score of urban students is $\mathrm{M}=5.92, \mathrm{SD}=2.43$ and the mean score and standard deviation score of rural students is $\mathrm{M}=7.52, \mathrm{SD}=2.83$. Since the calculated $\mathrm{t}$-value 3.03 is greater than the critical t-value i.e. 1.98 at 0.05 level of significance. Therefore the result reveals that there is a significant difference between health adjustment of urban and rural college students. From the mean score it is found that urban college students are better adjusted in health adjustment as compared to rural college students because as per the manual high score indicate unsatisfactory health adjustment. This result could because of the unavailability of proper medical facility and health guidelines in rural areas. There are number of studies conducted on this dimension which supports this finding. Langner (1962) conducted a study on health adjustment among rural and urban college students and conclude that rural students face more problems than urban students, especially girls. Nanda (2001) reported that urban college students had better health than the rural college students.

Table 4.7 shows the t-value of social adjustment dimensions of rural and urban college student. It indicates the mean score and standard deviation score of urban students is $\mathrm{M}=5.92, \mathrm{SD}=2.43$ and the mean score and standard deviation score of rural students is $\mathrm{M}=9.52, \mathrm{SD}=2.31$. Since the calculated $\mathrm{t}$-value 1.08 is less than the critical t-value i.e. 1.98 at 0.05 level of significance. So the result reveals that there is no significant difference between social adjustment of urban and rural college students. There are some studies conducted on this dimension which contradict to this finding. Sujatha et.al. (1993) studied adjustment problems among urban and rural college students and reported a significant difference in the social adjustment of urban and rural college students. Another study by Sulthana et.al. (1981) conducted a comparative study on social adjustment among urban and rural college students and reported that urban students were more socially adjusted as compared to rural students.

Table 4.8 shows the t-value of emotional adjustment dimensions of urban and rural college students. It indicates the mean score and standard deviation score of urban students is $M=16.14$, S.D $=4.75$ and the mean score and standard deviation of rural students is $M=18.54, S . D=4.28$. Since the calculated $t$-value 2.66 is greater than the critical t-value i.e. 1.98 at 0.05 level of significance. Therefore the result reveals that there is a significant difference between emotional adjustment of urban and rural college students. From mean scores it is found that urban college students are more emotionally stable as compared to rural college students because as per the manual high scores indicate unstable motion. This result could be due to the reason that urban college students have more social networks and friend circles as compared to rural college students. There are number of studies which support this finding. Dhoudiyal (1984) studied emotional disturbance of 276 adolescents randomly selected from urban and rural intermediate colleges with the help of emotional disturbance inventory developed by Rawal (1983). The result revealed that rural college students were more emotionally disturbed than the urban college students. Sulthana et.al. (1981) conducted a comparative study on emotional adjustment among urban and rural college students and reported that urban students were more emotionally adjusted as compared to rural students.

Hypothesis 4 stating "There will be a significant difference in health, social and emotional problems faced by the students studying in the urban and rural colleges" is accepted in the areas of home, health, emotional and educational adjustment but is rejected in the area of social adjustment.

\section{LIMITATIONS OF THE STUDY}

The present study had its own limitations, some of which are as follows:

1. The study was confined to only one rural and one urban college of Jammu region.

2. Small sample size of only 100 students are selected which is too small to generalize the findings

3 The study was confined to only Govt. colleges.

4. The study was confined to only Jammu District.

\section{CONCLUSION}

\section{Conclusion, Implications And Suggestions}

On the basis of present study it can be concluded that girls are average in health and social adjustment and unsatisfied in emotional adjustment. The boys are average in social adjustment and unsatisfied in health and emotional adjustment. The girls and boys do not differ significantly in health, social and emotional adjustment. The study also concluded that urban and rural college students differ significantly in health and emotional adjustment and do not significantly differ in social adjustment. 
Health, social and emotional problems of college students.

\section{IMPLICATIONS}

The result shows that boys and girls are found average and unsatisfied in health, social and emotional dimension of adjustment. Adjustment is very important as it is a process by which an individual learns certain ways of behaviour to cope with situation. Only an adjustable person can make his life successful

- So college authorities and parents should pay attention to minimize the adjustment problems of college going students.

- Appropriate interventions programs can be planned to assist college students who have problems in coping with the demands and challenges which can create stress and tension to their life in campus.

- General information on perceived academic, social and cultural issues in campus environment should be provided in order to make students transition smooth.

As it is observed from the result that urban college students are better adjusted than the rural college students in health, emotional dimensions of adjustment. It may be due to poor financial conditions and unavailability of proper facilities in rural areas.

- Hence, the college authorities should give specific attention towards student's financial needs as serious financial problems could leave a negative impact towards their adjustment in college.

- College administration should organize health awareness programs. They should be made to aware about the available resources and services so that the students can easily take benefit from them.

\section{SUGGESTION FOR FUTURE RESEARCH}

No research is conclusive in real sense. Every research paves the way and carves the way for future research.

1. A sample of 100 students was taken in the present study. Same study can be conducted on a large sample.

2. The present study was confined to one rural and one urban college only. It can be expand to more such colleges for broader generalisation.

3. Similar study can be conducted to study the comparison between boys and girls students of urban college.

4. Similar study can be conducted to study the comparison between boys and girls students of rural college.

5. Similar research can be conducted in other regions of J\&K state to study adjustment problems.

\section{References}

[1]. Anita, K.M, (1994), Sex difference in adolescent's self concept and adjustment. Res highlights, 4:79

[2]. Anonymouus, (2004), Trends: Young people and emotional health and well being. School Health Edu. Unit, England, PP. 25-28.

[3]. Baker, R.W and Siryk, B (1984), Measuring adjustment to college journal of counselling Psychology, 31, $179-189$.

[4]. Cook S.L (1995), Acceptance and expectations of sexual aggression in college students (Versiel E K Trunik) Psychology of women quarterly.

[5]. Dhoundiyal, (1984), Home environment and emotional disturbance among adolescents Ind. J Psych., 59(2):17-22.

[6]. Dutta, M, Baratha, G and Goswami,U(1997), Health adjustment of adolescents Ind. Psych rev 48(2): 48(3) 84-86.

[7]. Dutta, M, Baratha, G and Goswami,U(1997), Social adjustment of adolescents Ind. Psych rev 50(2): 90-94.

[8]. Demir Meliksah, Urberg (2004), Friendship and adjustment among adolescents. Journal of Experimental child Psychology vol. 88.P.68-82.

[9]. Darwin, C. (1959), The origin of Species. London; Murray. J.

[10]. Enochs, wendy K. Reland, Catuerine B (2006), Social Adjustment of college Freshman; the importance of gender \& living environment. College students Journal, March.

[11]. Gerdes, H. \& Mallinckkrodt, B. (1994). Emotional Social, \& academic adjustment of college student: a Longitudinal study of retention. Journal of counseling 7 Development, 72 (11-3), 1-14.

[12]. Good, C.V. (1959), Dictionary of education, (P:6) Newyork: M C Graw-Hill Book company.

[13]. Guo, R. (1998), Social adjustment of male and female, Psychological review, 82, 72-76.

[14]. Holembek, G.N. and Wanderi, M.L. (1993), Individual and relational predictors of adjustment in first year college students. Journal of counselling psychology, 40, 73-78.

[15]. Howitt, D., \& Cramer, D. (2005) $3^{\text {rd }}$ ed. Introduction to statistics in psychology. England: Pearson education limited.

[16]. Jain, Prabha and Jandu, Krishna, (1998), A comparative study of school adjustment of adolescent girls and boys. J. Edu. Res. Extn. 35(2): 14-21

[17]. Kasinath, H.M.(1990), Adjustment between migrated Hindi and non-Hindi speaking students studying in Jawaahar Navodaya . The process of education, $9,8-10$.

[18]. Kurvilla, Maly, (2006), Sex and local difference in emotional adjustment of adolescents. J. Comm.Guid.res., 23(3) $285-291$.

[19]. Leelavathi, H.R.,(1987), Factors influencing adolescent adjustment Msc. Thesis, University Agric. Sci. Dhanwad..

[20]. Lama, M. (2010), Adjustment of college Freshman: The importance of Gender and Place of Residence. International Journal of Psychological Studies 2(1) 142-150.

[21]. Lazarus R (2001), Patterns of adjustment and human Effectiveness (Students Edition), Tokyo: M C Graw Hill Book Co. Inc.

[22]. Lagner, V.K. (1962), Local and sex difference in health adjustment of students.J. Comm. Guid.res 16(2): 200-235.

[23]. Mythili, B, Bharathi, T and Nagarathna, B (2004), Adjustment problems of adolescent students. J. Comm. Guid. Res.21(1):54-61.

[24]. Meraj Sulthana Ganor Saddique A, Arif Siddique (1981), Personality adjustment among rural \& Urban students. IJ clinical Psychology vol. (8).51-88.

[25]. Muni, A.K and Pavigrahi, B. (1997), Effect of maternal employment on school going children's adjustment problems, J Comm. Guid. Res. 14(3): 209-216.

[26]. Mcwhitner, B.T. (1997), Loneliness, learned resourcefulness, and self-esteem in college students (Electronic version). Journal of counselling and development, 75(6), 460-469.

[27]. Mohsin, S.M and Hussain, S. (1985), Mohsin-Shamshad hindi adaptation of bell adjustment inventory (Student Form) Patna: Acrovoice. 
[28]. Mangle S.K. (2006), Advanced educational psychology, Prentice hall of India, New Delhi.

[29]. Nanda, A.K. (2001), Health of high school students: a comparative study. Ind. Psych. Rev., 56(1): 2-7.

[30]. Palsane, M.N. (1970), Health and parental education as factors in personal adjustment Psych. Stu., 15: 55-58.

[31]. Pathak, R.D. (1970), Sex difference among school children in the area of adjustment Psych. Studies, 15: $120-122$.

[32]. Pradhan, G.C. (1993), Major adjustment of secondary school students as a function of types of school and sex. The Educational review,XICX,64,65,67.

[33]. Parameswaram, E.G., and Beena,C.(2004), An invitation to psychology, Hyderabad, Neelkamal publication Pvt. ltd., reprint 618621.

[34]. Rahamtullah, K. (2007), Adjustment among adolescent. Journal of social science research. 2: 53-64.

[35]. Roy, B., Ekka, A., Ara, A. (2010), Adjustment among university students. Journal for social Development. Vol.2. (2), ISDR. Ranchi.

[36]. Singh, A.k. (1995), A study of parent-child relationship and adjustment problem among preadolescent. An unpublished Ph.D. thesis, L.N.M.U. Darbhanga.

[37]. Sujatha,S,GGoankar,V, Khadi, P.B and Katarki, P.A.,(1993), Factors influencing adjustment among adolescents. Ind. Psy. Rev. 40(1-2): 35-40.

[38]. Sinha, A.k.P., and Singh, R.P. (1995), Adjustment inventory for college students. Agra: National psychological corporation.

[39]. Shalu and Audichya, S. (2006), A study in school adjustment of rural adolescents. Ind. Psych.rev. 66(2): $93-96$.

[40]. Thirugnanasambandam, N., (1990), A study of the influence of social structure on social behaviours disposition and adjustment among high school students in Coimbatore educational district. J. Edu.Res.Extn, 27(2): 111-118.

[41]. United states Department of Education, (2001), Descriptive summary of 1995-96 beginning post secondary students: Six years later. Retrieved April 28, 2003 from http://nces.ed.gov/pubs2003/2003151.pdf.

[42]. Writer, M.G., \& Bowers, C.D.(2007), Predictors of persistence to graduation: extending a model \& data on the transition to university model (Electronic version). Canadian journal of Behaviour science, 39(3), 220-234. 